\title{
The Influence of Non - material Incentives Based on Team Trust Cognition on Innovation Performance
}

\author{
Hui XU \\ Center for Industrial Policy and Management Research, \\ Wuhan University of Science and Technology, \\ No.947, Heping Avenue, Qingshan District, Wuhan, China \\ E-mail:694996720@qq.com
}

\author{
Yun-Mei LI \\ Center for Industrial Policy and Management Research, \\ Wuhan University of Science and Technology, \\ No.947, Heping Avenue, Qingshan District, Wuhan, China \\ E-mail: lymwust@163.com
}

\begin{abstract}
The new generation employees has gradually become the leading force of enterprise innovation. In order to improve the performance of the new generation employees, this paper is based on the characteristics of the employees' pursuit of social identity and value fit, from the cognitive theory, further study the possibility of using the nonphysical incentive to construct the team's trust cognition and improve the innovative performance of the innovative subject of the new generation employees. Through the structural equation model test, the team trust strengthens the link between the knowledge-sharing innovation team composed of the new generation staff, and plays a role in the non-material incentive and innovation performance. The paper have a certain reference for revealing the influencing factors of internal innovation environment and guiding the enterprises to establish the trust between the new generation employees through the relevant means to improve the innovation performance of the enterprise.
\end{abstract}

Key Words - the New Generation Employees; Non-material Incentives; Cognitive Theory; Team Trust; Innovation Performance

\section{INTRODUCTION}

To improve innovation performance is one of the key issues of concern to modern enterprises, especially the new generation of employees of this special group to become the main business innovation, the enterprise based on the new generation of employees to pursue social identity and value fit characteristics, to take targeted incentives It is one of the core issues that the enterprise is concerned about to stimulate the innovation enthusiasm of the employees and improve the innovation performance of the enterprises. At present, the research on the influencing factors of innovation performance is focused on the research of this problem, such as knowledge spillover [1], network power [2], and technical cooperation and embedded in the external cluster tendency.

Based on the perspective of internal factors such as knowledge sharing [3], how to motivate the knowledge sharing among the new generation of employees, to build knowledge sharing innovation team awareness, improve the performance in the black box is still to be explored. Based on the above analysis, this paper intends to choose non-material incentives [4] as independent variables to explore the new generation of employee incentives and internal innovation environment on the impact of innovation performance. Combing the existing literature, the current non-material incentive research there are the following questions: First, different types of employees on the incentive sensitivity is different, therefore, non-material incentives for different types of staff differences remain to be explored. The new generation employees will play a leading role in innovation [5]. Therefore, this paper selected the new generation employees explored the effect of non-material incentives on the innovation performance of the new generation employees. In the study of the relevance of non-material incentives and innovation performance, we focus on the logic of motivation that directly inspires the enthusiasm of the staff, and the cognitive theory [6] points out that cognition will gradually blur the focus of non-material motivational facts, replaced by a clear corporate image in the minds of employees. Therefore, the fundamental purpose of non-material incentives is not to stimulate the enthusiasm of the staff innovation, but to establish knowledge-sharing innovation team awareness. Therefore, this article intends to introduce this mediator variable to explore the influence of the team atmosphere of non-material incentive to the innovation activity, to transform the trust into a dynamic, Affect the behavior and decisionmaking of employees, and ultimately achieve the goal of enterprise innovation, which in the past few studies rarely involved.

Based on the above analysis, this study intends to combine the domestic and international research results to the new generation employees, from the cognitive theory, nonmaterial incentives to innovation performance Impact mechanism, and further explain the use of non-material incentives to build team trust to improve the possibility of innovation performance.

\section{THEORETICAL HYPOTHESIS}

\section{A. The Non - material Incentives and Corporate Innovation Performance}

Foreign scholars Mahan Tamham summed up on the new generation of employee incentive impact of the four factors are individual growth, work autonomy, business achievement, 
physical [7]. Based on the above four factors, this paper will conduct in-depth study on the non-material incentives of the new generation of employees from the three dimensions of promotion incentive, trust incentive and environmental incentive.

For the new generation of employees, the high turnover rate has become the label of such employees, when the enterprise platform cannot meet their growing needs, the staff often choose to turn around without hesitation. Therefore, the appropriate promotion channels and development space is one of the factors that affect the attitude of employees [4]. Trust incentives for the desire for individual growth and work autonomy of the new generation of employees, to give employees the right to work and the right to participate in the management of the right to participate in the management of the staff to improve the degree of self-improvement staff to adapt to the working environment and The enthusiasm of the task, the pursuit of social identity and value of the fit has become hidden in their hearts, the strong driving force. It is beneficial to enhance the cohesion and centripetal force of the enterprise and mobilize the enthusiasm and creativity of the employees. And the interpersonal environment can form a focus, So that employees focus on the activities to increase the value of the activities of the organization, Based on the above analysis, this paper proposes the following assumptions:

H1: Non-material incentives have a significant positive effect on innovation performance.

\section{B. The cognition role of Team Trust}

With the passage of time, cognition will gradually blur the focus of the fact of non-material incentives, replaced by the minds of employees to leave a clear corporate trust image, so the fundamental purpose of non-material incentives is to establish a team of employees trust awareness. Trust includes not only the expectations of other people's motives and intentions, but also the attitude of taking action on scenarios and risks [8]. Therefore, trust can be transformed into a driving force that affects the behavior and decision-making of the new generation of employees. And the trust relationship between employees and enterprises contains both rational and emotional components, which can be divided into cognitive team trust and emotional team trust [9].

\section{Non-material Incentives and Team Trust}

From the cognitive theory we can see that the trust of this intermediary variable can enhance the non-material incentive to the positive performance of innovation. And to form a team trust awareness, the most important premise is to understand the motives of the new generation of employees [10], the formation of motivation by the new generation of staff needs, values and other factors [10]. Commitment is an important factor in the establishment of trust, business promotion to learn opportunities and promotion space is both a long-term incentive for employees is an indirect commitment to enterprises and employees to establish long-term joint development of cooperative relations, and benefit from the promotion mechanism for employees to bring reference to other employees guide the role of staff can be inspected Enterprises to implement the commitment to deepen the credibility of enterprises [11]. Trust in the incentive of leadership and improve the generation of new staff to participate in the degree of enterprise management itself is a kind of trust behavior, team members of the enterprise status and implementation of the content have a full understanding, and more objective measures linked to guide the staff awareness of the implementation of the credibility of the innovation team to deepen the awareness [11]. And environmental incentives for the new generation of staff to form an open and frank communication and feedback culture, reduce staff opportunism and free rider behavior, greatly improve the staff's job satisfaction; and corporate culture can be directly guided by the leadership of the Has a preliminary form of awareness to be shaped, and enhance corporate cohesion and centripetal force, the formation of team trust awareness. Based on the above analysis, this paper makes the following assumptions:

H2: Non-material incentives have a significant positive effect on team trust

\section{Team Trust and Corporate Innovation Performance}

For a long time, the reason why enterprises establish team trust through relevant incentive means that the trust of the team directly affects the employee's work initiative. However, in the innovation environment with knowledge sharing as the background, the team trust affects the innovation performance Mechanism: through rational and emotional.

In the trust of the cognitive team, the vulnerability of trust to make employees more likely to accept the outside world, to accept cooperation between employees And the management of managers, so the team trust can maintain the order of enterprise management at a lower cost, and promote the occurrence of cooperative behavior. The occurrence of behavior, reduce the cost of supervision and reduce the barriers to management, creating a sustainable innovation atmosphere and innovative performance. In the emotional state of this trust, both sides are willing to use an open mind and standards to assess each other's behavior, reduce barriers to communication, support each other's work to meet each other's excess demand to promote innovation; and reduce the team's opportunism and Free ride phenomenon. This high degree of trust leads to a reduction in self-protection and defensive behavior that increases the level of co-operation and knowledge sharing among employees, enabling employees to focus more on creating value for the organization and to promote innovation performance. Based on the above analysis, this paper proposes the following assumptions:

H3: Team trust has a significant positive impact on corporate innovation performance

H4: Team trust plays a mediating role in nonphysical incentives and innovative performance

Based on the above, this study is to build a theoretical model between non-material incentives, team trust and corporate innovation performance. 


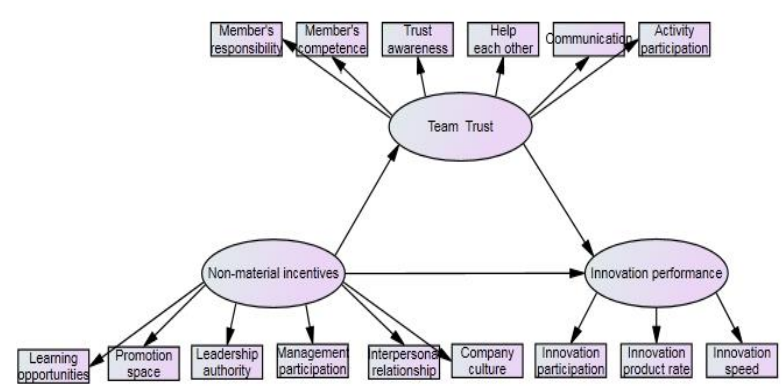

Figure 1. Conceptual model

\section{RESEARCH TEST}

\section{A. Data Collection}

This paper takes the new generation of employees as the research object, and uses online questionnaires to collect 256 questionnaires, the efficiency of the data was $82 \%$. The degree of undergraduate education and the above percent is $90 \%$. It can be seen that the sample data obtained from the questionnaire of this study are of good quality and meet the needs of the research object.

\section{DATA ANALYSIS}

\section{A. Reliability and Validity test of scale}

Before the validation of the model, the reliability and validity of the scale are tested first. In this study, Cronbach's $\alpha$ coefficient was used to test the reliability of the scale. The results are shown in Table 1.

TABLE I. RELIABILITY ANALYSIS

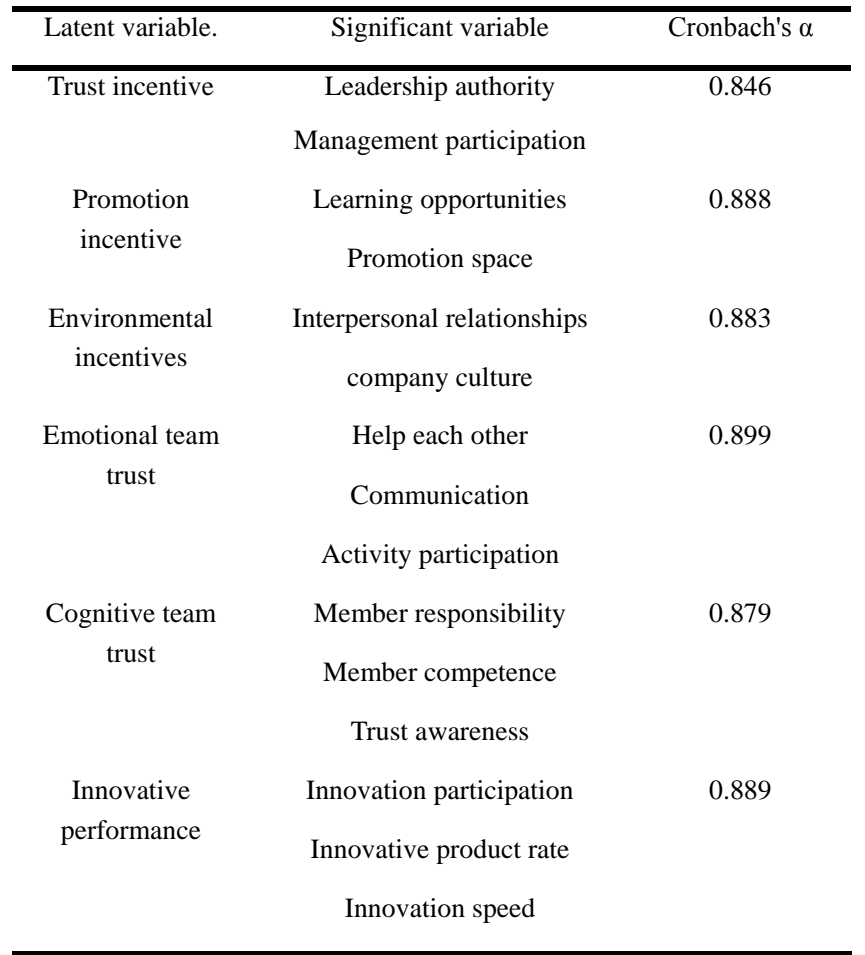

It can be seen from Table 2 that the Cronbach's $\alpha$ coefficient of the six latent variables is in the reliability range of $0.8-0.9$, indicating that scale has a high reliability level. The validity of the samples was tested by KMO and Bartlett spherical test. The results showed that the KMO was 0.847 (> $0.7)$, Bartlett had a spherical test sig of $0.000(<0.005)$, indicating that the validity of the sample data is better to support confirmatory factor analysis.

\section{B. Structural Equation Path Analysis Results}

The hypothetical model was carried out using AMOS21.0 software to verify the effect. The model contains 6 latent variables and 15 observed variables. The results of the fitting suitability test for the hypothetical model are shown in Table 3.

TABLE II. MODEL FITTING INDICATORS

\begin{tabular}{lllllllll} 
Classif & CMIN/ & RMR & RMS & GF & CF & TL & PN & PG \\
ication & DF & & EA & I & I & I & FI & FI \\
Result & 1.214 & \multirow{2}{*}{0.088} & 0.032 & 0.9 & 0.9 & 0.9 & 0.6 & 0.6 \\
& & & & 47 & 92 & 89 & 92 & 00
\end{tabular}

From Table 2, the experimental data can fit the theoretical model. According to the regression coefficient of the observed variables in the confirmatory factor analysis, the load factor of the sample is more than 0.80 , which means that the model has good basic adaptability and high structural validity. The calculation results of the structural path model for the variable path coefficients are shown in Figure 2.

It can be seen from Figure 2 that the non-material incentive has a positive effect on the innovation performance. The positive effect of the intermediary variable team trust on the innovation performance is more obvious, and the concrete mediation is shown in Figure 2.

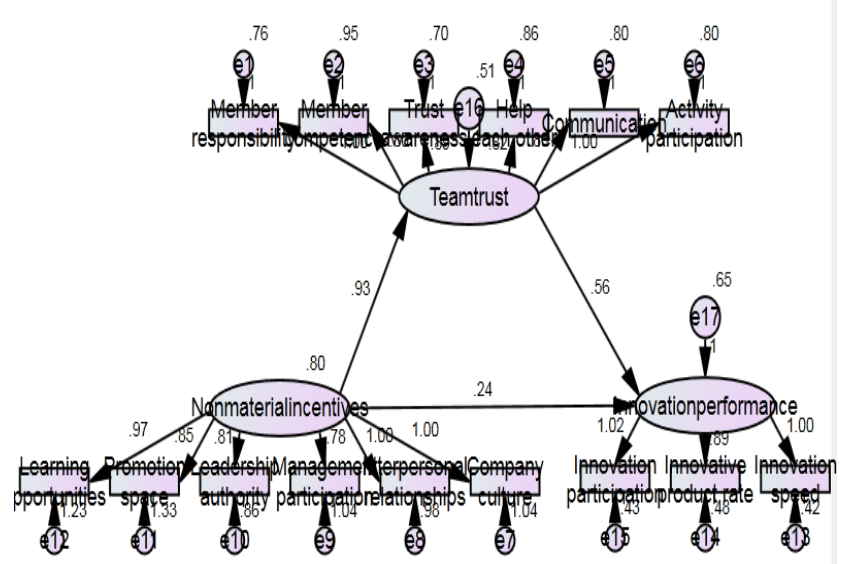

Figure 2. The Intermediary role of Team Trust

\section{CONCLUSION AND ENLIGHTENMENT}

\section{A. Conclusion}

On the basis of the study hypothesis, through the model validation analysis, the impact on non-material incentives, team trust and innovation performance draws the following conclusions: 
(1) The Environmental and trust incentive of material incentive have a significant positive effect on innovation performance, and the positive effect of promotion incentive on innovation performance is not significant. In view of the effect of promotion incentives on innovation performance is not significant, this study suggests that may be due to promotion incentives are long-term incentives, to some extent by the external environment of greater impact on the higher autonomy and adventurous new generation of staff In terms of the pursuit of innovation and self-worth pursuing, Therefore, the positive effect on innovation performance is not significant.

(2) Team trust cognition has an intermediary effect on non-material incentives and corporate innovation performance, in which the promotion incentive dimension of non-material incentives has no significant effect. And the promotion incentive of the emotional trust effect is not significant, this may be due to promotion incentives will increase competition among team members, resulting in increased employee self-protective and defensive behavior, but the promotion incentives can stimulate cognitive team trust, which indicates that the promotion incentives will form an objective evaluation between the team members, so company can choose whether to use according to the actual situation of the enterprise promotion incentive.

\section{B. Enlightenment}

(1) Pay attention to the characteristics of the new generation employees in pursuit of social identity and value fit, and implement the non-material incentive policy accordingly. Therefore, enterprises should set up a variety of public record platform, improve staff recommendation system to improve the staff's working enthusiasm; by describing the enterprise vision and target environment incentives to corporate goals and personal goals, enhance corporate cohesion and centripetal force, the formation of attention to focus, so that employees focus on the activities for the organization to create value.

(2)Build a knowledge-sharing team innovation atmosphere, gather enterprise innovation resources, improving the level of collaborative innovation. Therefore, enterprises should adopt a vision and participatory management to encourage informal knowledge sharing among employees; improve the credibility of employee perception and implementation; Through the association of incentives to create new integration goals and common interests of the foundation to reduce the competition between the team members to encourage exchanges and cooperation between each other; to enhance mutual recognition among team members, to promote and build enterprise knowledge sharing model development and improvement.

\section{REFERENCES}

[1] J.P.Yang, N.Hou, L.Wang. Knowledge spillover, knowledge potential and cluster innovation performance in cluster $[\mathrm{J}]$. Journal of Management Engineering, 2016(3):27-35

[2] H.Y, G.H.Chen. Study on the Relationship between Network Power and Innovation Performance of Cluster Enterprises [J]. Chinese Journal of Management, 2016(6):855-862
[3] X.Y.Ge, Q.X.Ww, S.M.Zhao. Study on the relationship between learning orientation, team trust and enterprise innovation performance based on science and technology enterprises [J]. Chinese Journal of Management, 2016(13):996-1002

[4] Maslow. A Theory of Human Motivation [J]. Psychological Review, 1943, 50 (4): 370-396

[5] Westerman..J.W, Yamamura. Generational Preferences for Work Environment Fit: effects on employees outcomes [J] .Career Development International, 2014, 12 (2): 150-161

[6] Neisser.U. Cognitive Psychology [M]. New York: Appleton Century Crofts, 1967.

[7] Amar. Knowledge Workers to Innovate [J]. European Journal of Innovation Management Bradford, 2004 (1): 89

[8] Lewick.R.J, Bunker.B.B Developing and Maintaining Trust in Work Relationships $[\mathrm{M}]$. Trust in Organization: Frontiers of Theory and Research, Sage, Thousand Oaks, Ca, 1996: 114-139

[9] Mcllister. Affect-and Cognition-Based Trust as Foundations for Interpersonal Cooperation in Organizations [J]. Academy of Management Journal, 1995 (1): 24-59

[10] Y.X.Zhao. The relationship between job characteristics and the happiness of the new generation of employees - based on the theory of self-determination [D]. Nanjing, Nanjing University, 2016

[11] Ana Cristina Costa. Work Team Trust and Effectiveness [J]. Personnel Review, 2003 (5): 605-622 